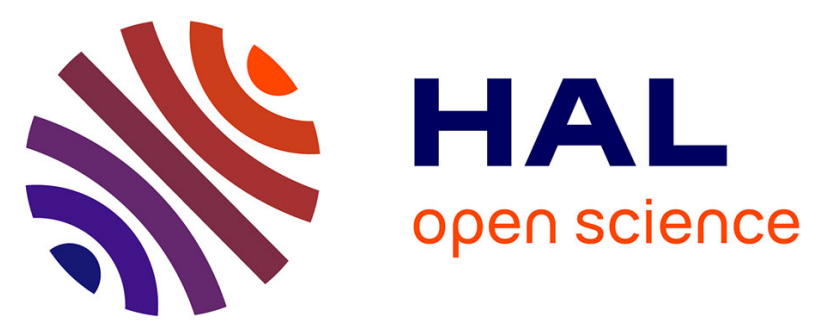

\title{
Convergence of stakeholders' environmental threat perceptions following mass coral bleaching of the Great Barrier Reef
}

Lauric Thiault, Matthew I Curnock, Georgina G Gurney, Scott F Heron, Nadine A Marshall, Erin Bohensky, Nao Nakamura, Petina L Pert, Joachim

Claudet

\section{To cite this version:}

Lauric Thiault, Matthew I Curnock, Georgina G Gurney, Scott F Heron, Nadine A Marshall, et al. Convergence of stakeholders' environmental threat perceptions following mass coral bleaching of the Great Barrier Reef. Conservation Biology, 2021, 35 (2), pp.598-609. 10.1111/cobi.13591. hal-03186352

\section{HAL Id: hal-03186352 https://hal.science/hal-03186352}

Submitted on 31 Mar 2021

HAL is a multi-disciplinary open access archive for the deposit and dissemination of scientific research documents, whether they are published or not. The documents may come from teaching and research institutions in France or abroad, or from public or private research centers.
L'archive ouverte pluridisciplinaire HAL, est destinée au dépôt et à la diffusion de documents scientifiques de niveau recherche, publiés ou non, émanant des établissements d'enseignement et de recherche français ou étrangers, des laboratoires publics ou privés. 


\section{Convergence of stakeholders' environmental threat perceptions 2 following mass coral bleaching of the Great Barrier Reef}

3 Prepared as a Contributed Paper for Conservation Biology

4 Running Title: Convergence of environmental threat perceptions

Authors: Lauric Thiaultt ${ }^{a, b}$, Matthew I. Curnockc, Georgina G. Gurney ${ }^{d}$, Scott F. Heron ${ }^{\text {e,f }}$, Nadine

A. Marshall'c, Erin Bohenskyc, Nao Nakamurac, Petina L. Pert', Joachim Claudet ${ }^{a, b}$

\section{Affiliations:}

${ }^{a}$ National Center for Scientific Research, PSL Université Paris, CRIOBE, USR 3278 CNRSEPHE-UPVD, Maison des Océans, 195 rue Saint-Jacques, 75005 Paris, France

'Laboratoire d'Excellence CORAIL, Moorea, French Polynesia

${ }^{c}$ CSIRO Land and Water, James Cook University, Townsville, QLD, 4811, Australia

${ }^{\mathrm{d} A R C}$ Centre of Excellence for Coral Reef Studies, James Cook University, Townsville, Queensland, Australia

ePhysics and Marine Geophysical Laboratory, College of Science and Engineering, James Cook University, Townsville, Queensland, Australia

${ }^{f}$ Coral Reef Watch, US National Oceanic and Atmospheric Administration, College Park, MD, USA

\section{Word count: 6,128}

Keywords: attitudes; climate change; coastal communities; environmental change; environmental threats; Great Barrier Reef; media; public perceptions; risk assessment

\section{Abstract}

Managing human use of ecosystems in an era of rapid environmental change requires an understanding of diverse stakeholders' behaviors and perceptions to enable effective prioritization of actions to mitigate multiple threats. Specifically, research examining how threat perceptions are shared or diverge among stakeholder groups, and how these can evolve through time, is increasingly important. Here, we investigate environmental threat perceptions related to Australia's Great Barrier Reef and explore their associations before and after consecutive years of mass coral bleaching. Using survey responses from 2013 and 2017 involving commercial fishers, tourism operators, and coastal residents $(n=5,254)$, we 
32 found that the threats perceived as most serious by these groups differed substantially in 33 the pre-bleaching period but became strongly aligned post-bleaching. Climate change

34 became the most frequently reported threat by all stakeholder groups following the coral 35 bleaching events, and perceptions of fishing and water quality also ranked high. For the 36 three stakeholder groups of fishers, tourism operators, and coastal residents, the 37 prioritization of these three threats tended to diverge in 2013 , but convergence became 38 evident post-bleaching. These results indicate an emergence of areas of agreement within 39 and across stakeholder groups. Changes in perceptions were likely influenced by high profile

40 environmental disturbance events and media representations of attributable threats. Our 41 study provides insights into the plasticity of environmental threat perceptions and highlights 42 how their convergence in response to major events may create new opportunities for 43 strategic public engagement and increasing support for management actions. 


\section{Introduction}

Stakeholder support for conservation and environmental management initiatives is key to their successful implementation (Bennett \& Dearden 2014; Alexander et al. 2018). Failure to secure community support can lead to public resistance and backlash from stakeholders, non-compliance and ultimately, a lack of achievement of social and ecological objectives (Pollnac et al. 2010; Gurney et al. 2014). Different perceptions among different users and audiences about the relative seriousness of environmental threats is often at the heart of such resistance, affecting public support for management strategies designed to respond to those threats (Voyer et al. 2013).

People perceive environmental threats in diverse ways. Complex threats like climate change are characterized by great variation in perceptions and experience, such that no unifying theory is applicable (Wolf \& Moser 2011). This is because risk judgement, where individuals assess risks based on the probability of a threat and its relative consequences, incorporates considerations such as personal worldviews, affiliation and proximity, emotional affect, and trust (Slovic 1999; Elliott 2003). These risk assessments are mediated by a variety of societal determinants including experiential and sociocultural factors like social norms and cultural cognition (Slovic 1999; Kahan \& Braman 2006; Gattig \& Hendrickx 2007). Furthermore, they are amplified or attenuated by institutions such as the media and political systems (Kasperson \& Kasperson 1996; Voyer et al. 2013; Foxwell-Norton \& Lester 2017). As a result, perceptions may differ greatly among social subgroups (e.g. livelihood groups).

The socially constructed nature of environmental threat perceptions also raises the question of how sensitive such perceptions are to contextual change, including environmental change. Indeed, in addition to potentially affecting individuals' personal experiences, environmental crises often attract increased levels of media coverage of the threat in question, which may lead to shifts in public concern over certain issues (Carmichael \& Brulle 2017; Curnock et al. 2019). However, the social effects of such crises are context-dependent, and such shifts in concern only happen in amenable public arenas, where widely shared cultural, institutional and political conditions enable sustained attention to the crisis (Ungar 2014). Analyzing how threat perceptions within a community change in response to events or shocks within a social-ecological system can help to better understand the emergence 
and dissipation of common and conflicting perceptions, and identify the key drivers of these changes (Siegrist 2013). Such knowledge is valuable for resource managers seeking to engage successfully with communities to raise awareness and encourage participation in the design and implementation of socially relevant management actions (Kochalski et al. 2019). However, despite recognition of the potential plasticity of community perceptions of environmental threats, most assessments of perceptions are static and the temporal dynamics are rarely studied explicitly (Siegrist 2013).

In order to fill this gap, we set out to evaluate changes in stakeholders' perceptions of key environmental threats in the context of a major environmental disruption. Specifically, we examine the prioritization of environmental threats within and among three distinct stakeholder groups (commercial fishers, tourism operators, and coastal residents) in the Great Barrier Reef (GBR or Reef) region, Australia, before and after the unprecedented and wide-spread climate-change induced coral bleaching events in 2016 and 2017 (Hughes et al. 2018a, 2018b). We ask: (1) Do fishers, tourism operators, and coastal residents perceive environmental threats differently? (2) What are the positive and negative associations between the identified threats? (3) Did threat prioritization and associations within and among stakeholder groups change following the mass coral bleaching events? The GBR represents an important case study to help improve our understanding of the responsiveness of environmental threat perceptions to major risk events among interest groups and the general public. This importance is underpinned by its World Heritage and iconic status, the multiple uses and dependencies of adjacent communities and industry sectors, the complexity of threats it faces from local to global scales, and the myriad intangible social and cultural values with which it is associated (Gurney et al. 2017; Marshall et al. 2019a; Curnock et al., 2019). It is hoped that our study will provide social scientists, conservation practitioners and resource managers with an improved understanding of the dynamic nature of environmental threat perceptions, to facilitate more purposeful and effective public engagement around threat mitigation in their responses to future risk events.

\section{Methods}


The Great Barrier Reef (GBR) is the largest coral reef system in the world, spanning 2,300 km along the east coast of Queensland, Australia. Despite being considered one of the best managed systems globally (McCook et al. 2010), live coral cover has declined by an average of $0.67 \%$ /year since 1996 as a result of cumulative impacts from multiple, interacting threats (Mellin et al. 2019). Through an evidence-based assessment process, the Great Barrier Reef Marine Park Authority (GBRMPA) has consistently identified climate change as the greatest threat to the GBR since 2009 (GBRMPA, 2009; 2014; 2019a). Other major threats identified through this process include poor water quality (i.e., nutrient, sediment and pesticide runoff), coastal development, some remaining impacts of fishing and illegal fishing and poaching, and outbreaks of Crown-of-Thorns Starfish (COTS). Collectively these threats have resulted in a downgrading of the overall outlook for the GBR from "poor" (GBRMPA 2009, 2014) to "very poor" in recent years (GBRMPA 2019a).

In response to these assessments, a series of management interventions aimed at protecting biodiversity and increasing ecosystem resilience have been developed (Great Barrier Reef blueprint for resilience 2017). Further, a variety of community engagement initiatives and programs led by GBRMPA (e.g. Eye on the Reef, Reef Guardian, Reef Joint Field Management Program, Local Marine Advisory Committees, Reef Advisory Committees) have provided avenues to foster stakeholders' support for management and engagement in stewardship activities.

\section{GBR stakeholder groups}

We compared threat perceptions among three key stakeholder groups of the GBR region, namely commercial fishers, tourism operators and coastal residents. These groups have different levels and types of direct interaction with the GBR and therefore, we hypothesized may have different threat perceptions. The former two groups represent the two largest reef-dependent industries on the GBR region, but they engage with the Reef in different ways and have distinct socio-demographic and political characteristics (Curnock et al. 2014; Tobin et al. 2014). GBR tourism operators tend to be entrepreneurial, have achieved a high level of education, and are sensitive to tourists' perceptions and media representations of GBR threats (Curnock et al. 2014, 2019; Curnock \& Marshall 2019). Commercial fishers have been found to be a relatively homogeneous male-dominated group, and tend to be older 
134 and more politically conservative than tourism operators (Tobin et al. 2014; Marshall \& Curnock 2019a).

\section{Data collection and coding of threats}

Data on environmental threat perceptions was elicited through surveys with 5,254 individuals in $2013(n=3,304)$ and $2017(n=1,950)$ as part of the Social and Economic LongTerm Monitoring Program (SELTMP) for the GBR (Marshall et al. 2016). In the 2013 survey, respondents included 2,975 coastal residents, 210 commercial fishers and 119 owners and managers of marine and island tourism businesses operating in the GBR. In the 2017 survey,

142 they included 1,765 coastal residents, 91 commercial fishers and 94 tourism operators.

143 National and international tourists were also surveyed in the SELTMP but were not included

144 in this analysis because this paper focuses on local stakeholders. Coastal residents and

145 tourists were surveyed using face-to-face interviews in the main population centers along 146 the GBR, and tourism operators and commercial fishers were interviewed by telephone. For 147 both the 2013 and 2017 sampling periods, the research was reviewed and approved by the 148 CSIRO Social Science Human Research Ethics Committee, and was conducted in accordance with the Australian National Statement on Ethical Conduct in Human Research (2007).

150

To elicit threat perceptions, respondents were asked to list the "three most serious threats to the GBR" in a short, open-ended format. Responses were collated and then each was numerically coded ( $1=y e s ; 0=$ no) into 13 broad thematic categories (Table 1 ; these categories are described further in Curnock et al. (2019)). The coding and analysis did not take into account the ranking or order of threats as listed by the respondents. The SELTMP surveys also obtained information on gender and age, which have been shown to influence perceptions (Jefferson et al. 2014) and were thus used to control for unbalanced sampling across years (Supporting Information). Additional details on survey design and administration in the SELTMP are available at (CSIRO 2019).

\section{Data analysis}

We explored changes in threat perceptions through three distinct analyses. First, we focused on the change in occurrence of threats over time within stakeholder groups. For each of the 12 threat categories ("other" was excluded), we used a general linear model (GLM) with a binomial fit, where the response variable was threat occurrence and the predictor variables 
were stakeholder group membership, year, gender and age. An interaction between group membership and year was examined to elucidate whether perceptions of the threat differed significantly across the two time periods for different groups. Demographic variables were included to control for bias in unequal distribution of samples on both years.

Second, for each threat category we assessed the variation in threat occurrences in each year among stakeholder groups. We used GLMs with a binomial fit of threat occurrence as a function of stakeholder group, gender, and age and quantified the variation in the response that was explained by the 'stakeholder group' covariate using the models' estimated variance.

Third, we examined the associations between perceived threats in each stakeholder group using probabilistic models of threat co-occurrence. Expected frequency of co-occurrence was determined based on the distribution of each threat being random and independent of the other threats. We compared the observed and expected frequencies of co-occurrence between each pair of threats to determine which threats tended to be statistically more or less identified together than expected by chance. All analyses were implemented in $R$ statistical analysis software version 3.6.2 (R Core Team 2017).

\section{Results}

Analysis of within-stakeholder group perception changes revealed both significant increases and decreases in the occurrence of several threats from 2013 to 2017 (Fig. 1). The direction of these changes was generally consistent across the three stakeholder groups. Between 2013 and 2017, most notably, there was an increase in the perceived threat of 'climate change' across all groups (though not significant for tourism operators because it was already considered a priority threat by this group in 2013), with commercial fishers showing the largest relative shift. 'Pollution' also became more frequent among the three threats perceived as most serious to the GBR, although increases were only significant for coastal residents and tourism operators. The proportion of respondents perceiving 'coastal development' and 'shipping' among the top three threats fell significantly across all groups. The occurrence of 'fishing' increased sharply among fishers, and decreased slightly (but significantly) among residents. Over the four-year sampling interval, the occurrence of 'poor water quality' also decreased for all stakeholder groups, but the change was only significant 
for residents. Although significant for residents, the magnitude of the changes in occurrence probability remained relatively low for other threat categories (Fig. 1).

196

197

198

199

200

201

202

203

204

205

206

207

208

209

210

211

212

213

214

215

216

217

218

219

220

221

222

223

In 2013, threats that were perceived as being the most serious for the GBR differed between stakeholder groups (Fig. 2). Fishers were primarily concerned with 'coastal development' $(p=0.38)$, while tourism operators were most concerned about 'poor water quality' $(p=0.40)$, and coastal residents indicated 'shipping' as the most serious threat ( $p=0.36)$. In 2017, however, 'climate change' became the threat most likely to be identified among the top three most serious threats to the GBR by all stakeholder groups (fishers: $p=0.43$; operators: $p=0.53$; residents: $p=0.55)$. 'Fishing' was the second threat most likely to be mentioned by fishers $(p=0.42)$ and ranked third for tourism operators $(p=0.23)$ and residents $(p=0.26)$. Other environmental threats that ranked high in 2017 included poor water quality (fishers: $p=0.30$; operators: $p=0.27$; residents: $p=0.22$ ), governance (fishers: $p=0.21$; operators: $p=0.23$ ) and pollution (residents: $p=0.45$ ).

In 2013, it was also noted that there was significant variation among stakeholders in their perceptions for all threats except 'poor water quality', with stakeholder group accounting for $12 \%-34 \%$ of the variation in threat perceptions (Fig. 3). Fishers tended to list 'climate change' significantly less frequently than tourism operators and coastal residents. Residents listed 'pollution' and 'shipping' more frequently than other groups. Although not statistically significant, tourism operators tended to identify 'poor water quality' and 'climate change' more frequently than fishers and residents. The variation among stakeholders decreased markedly in 2017, with the variable 'stakeholder group' accounting for just $6 \%-16 \%$ of the variation in environmental threat perceptions (Fig. 3). The largest variations in 2017 were in 'pollution' and 'fishing', which occurred more frequently among residents and fishers, respectively.

In 2013, interactions between the perceived key threats did not overlap among the stakeholder groups and revealed more negative associations than positive associations for all three stakeholder groups (Fig. 4). For example, 'climate change' was negatively associated with 'natural disasters', 'coastal development' and 'pollution' for fishers; with 'fishing' and 'mining' for tourism operators; and with 'COTS' for coastal residents (Fig. 4). In the fishers' network, two other negative associations ('pollution' with 'poor water quality'; and 'fishing' 
with 'governance') and one positive association ('natural disasters' with 'mining') were evident. In the tourism operators' network, 'coastal development' was negative associated with 'governance', while 'pollution' significantly co-occurred with 'shipping'. In the residents' network, negative associations between 'COTS' and 'governance', and between 'fishing' and the 'pollution'-'humanity' positive association cluster were identified. Contrary to 2013, interactions between the key perceived threats in 2017 revealed more positive than negative associations, with clear overlap between stakeholder groups (Fig. 4). 'Climate change' formed new positive associations with 'fishing' and 'poor water quality' for all stakeholder groups. In the fishers' network, 'fishing' and 'poor water quality' became also positively associated. Tourism operators' and residents' networks both displayed a negative association between 'climate change' and 'COTS'; for the operators' network, this negative association was part of an interactions cluster of 'COTS' (negative) with 'climate change' and 'poor water quality' (positive).

\section{Discussion}

Community and stakeholder support is often critical for conservation success.

Understanding community perceptions of environmental threats, and how these may vary between social subgroups and over time is therefore important for guiding strategic engagement and policy development. Our analysis of environmental threat perceptions of commercial fishers, tourism operators, and coastal residents with respect to the GBR across two time periods revealed three key results. First, environmental threat perceptions can shift in a relatively short time in response to contextual changes. Second, following a major environmental disturbance event, stakeholder groups increasingly identified similar threats, both between and among groups. Lastly, the perceived threat of climate change rose to become the most prominent source of concern for each of the stakeholder groups.

\section{Plasticity of environmental threat perceptions}

The major shift in threat perceptions over a relatively short time period in our case study points to the plasticity of these perceptions. Whilst recent studies indicate that people do not consider the media a trusted source of information about the GBR (MacKeracher et al. 2018), they also acknowledge the media's centrality in communication about environmental issues (Foxwell-Norton \& Lester 2017). The majority of the public, including those who live 
closest to the GBR, have little direct experience of the Reef and rely on visual representations largely shaped by information and knowledge communicated through the media. In our case, the observed changes in threat perceptions appear to reflect the relative prominence of different threats communicated in the media. For example, the grounding of a coal carrier on a shoal in the GBR in 2010 and controversy over the Abbot Point Capital Dredging Project in 2013 received extensive media coverage at the time, and were considered likely to have influenced public perceptions of the risks posed by shipping and coastal development to the GBR (Lankester et al. 2015). We suspect that the visibility of these two events in the media influenced the high degree of concern about these threats in the 2013 survey. In the 2017 survey, however, our results reveal that climate change became the foremost issue for all local stakeholder groups. The extent, magnitude and ecological impact of the 2016 and 2017 mass bleaching events (Hughes et al. 2018a, 2018b) and the considerable attention from the media that explicitly attributed the events to climate change likely increased people's concerns about this issue (Eagle et al. 2018; Curnock et al. 2019; Boudet et al. 2019). Together, these results indicate that shifts in perceptions were related in part to changes in the predominance of particular issues in the media (Lee et al. 2015; Boudet et al. 2019), and are suggestive of the media's importance and likely influence on public perceptions.

272 Media constructions of threats to the GBR have been implicated in the divergence of 273 perceptions held by the public and those of managers regarding which threats are most 274 critical (Moscardo 2008). The contribution of journalistic norms, whereby some issues are 275 given primacy in reporting over others (Boykoff \& Boykoff 2007), may provoke or further 276 exacerbate such incongruity (Voyer et al. 2013). For instance, some have proposed that 277 increased attention to plastic pollution in the media over recent years may have a 278 "crowding-out effect" on the urgency of other threats for which the consensus among 279 scientists and managers is better established, such as climate change (Stafford \& Jones 280 2019). However, our results from 2017 do not show a negative association between 281 'pollution' and 'climate change' (or any other threat), disputing the presence of such an 282 effect in our case. Although it should be noted that a high proportion of residents cited 283 plastic pollution as a key threat to the GBR (Supporting Information). 
In 2017, after the GBR experienced some of the worst and most widespread effects of climate change on live coral (Hughes et al. 2018a) and associated fish assemblages (Richardson et al. 2018), climate change was the most frequenlty mentioned threat for all stakeholder groups (42-55\% of the 2017 sample). Our finding that $55 \%$ of coastal residents perceive climate change in the top three threats to the GBR only partly aligns with results from a report (based on data from the same survey that we employed) that found that $68 \%$ of respondents considered climate change "an immediate threat requiring action"; Marshall \& Curnock 2019). This discrepancy may be because the latter question relates the threat of climate change in general terms, while our paper examines the threat of climate change to the GBR specifically.

While many news media representations of the 2016-17 mass coral bleaching events attributed climate change as the cause (Eagle et al. 2018), there was a concurrent "alternative facts" campaign in Australia run by vested-interest groups and conservative news media that denied the climate change attribution (Opray 2019). Survey respondents' political orientation and their primary sources of news in relation to the coral bleaching event could have influenced their threat perceptions and acceptance of climate change as the cause of recent mass bleaching (Lee et al. 2015). As climate-related environmental communication campaigns are susceptible to polarization and misinformation, managers and scientists face serious challenges in a media landscape that is increasingly susceptible to the intentional dissemination of misleading content (van der Linden 2019). In Australia, this is confounded by a highly concentrated media ownership (Holmes \& Star 2018) and increasingly skeptical climate change reporting (Bacon 2013).

We note that in the Austral summer of 2020, a third climate-induced mass coral bleaching event occurred in the GBR, coinciding with the onset of the global COVID-19 pandemic. The concurrence of these two major events raises questions about whether public perceptions about the threat of climate change have increased in prominence, or if the pandemic has "crowded-out" such concerns by affecting reporting opportunities related to this last bleaching event. Further studies may be able to elucidate the relative effects of these historically significant events. 
Achieving consensus among stakeholders is a persistent challenge with consequences that can affect the success of decision-making (Hicks et al. 2013). Shared perceptions within the community can help practitioners identify joint management goals and reduce disagreement between different stakeholder groups that potentially hold dissimilar knowledge and values (Sutton \& Tobin 2009; de Nooy 2013). Increased similarity in perceptions of the most serious threats to the GBR across stakeholder groups in 2017 suggests that GBR managers may be better situated to develop management strategies that are likely to receive broad-based support (Horowitz et al. 2018). Our findings also suggest which strategies are likely to work well in public communication because they are directed towards threats that resonate with the majority of stakeholders. In particular, climate change, which now ranks at the top of the list across all stakeholder groups, may represent a relevant entry point for engagement with other relevant issues that also ranked high among fishers, tourism operators and residents, such as water quality and fishing. This also suggests that most people would accept GBRMPA's framing that links climate change resilience to improved water quality and strong fishing regulation (GBRMPA 2019b), and highlights a potential window of opportunity for managers to engage with synergistic policy interventions to protect the Reef and other ecosystems (Morrison et al. 2019).

Although threat perceptions held by the different stakeholder groups became more aligned in 2017, some differences remained. Commercial fishers were increasingly concerned about the threat posed by fishing, with concerns centered around overfishing ( $50 \%$ of fishing threats were related to overfishing; Supporting Information). Whether they considered themselves as contributing to overfishing was not explored further in our survey. However, given that $40 \%$ of identified fishing threats related to recreational fishing, it appears that many commercial fishers did not consider their group responsible for the threat. Coastal residents were substantially more concerned about pollution (Fig. 1), including plastic pollution (Supporting Information). This may be because residents' first-hand experience of the GBR is generally limited to local beaches where the most visible threat is marine debris

342 (Marshall et al. 2019b). Further, recent years have seen significant media coverage of the 343 threat of plastic pollution to global ocean environments (Stafford \& Jones 2019). 
344 Identifying and engaging key stakeholder groups is important, but such groups are rarely 345 homogenous (D’Anna 2016). As a result, decision-makers looking for consensus by focusing 346 engagement on the most serious threats may neglect potentially complex interactions that 347 could lead to sub-optimal outcomes. For example, there is a risk that apparent similarities 348 between stakeholder groups may mask conflicts within these groups that, if not addressed, 349 would ultimately affect whether individuals support management actions. Our analysis of 350 the associations between threats found that most negative associations present in 2013 351 were absent four years later. Instead, positive associations between high-priority threats 352 (i.e. 'climate change', 'poor water quality', and 'fishing') became evident within all 353 groups, suggesting that addressing these threats may now be perceived as complementary.

354 While the most frequently mentioned threats were increasingly identified together, some 355 negative associations remained in the post-coral bleaching period. The perception of COTS 356 as a serious threat tended to be negatively associated with those of climate change (among 357 tourism operators and residents) and water quality (for residents). In such cases, a key 358 challenge is to ensure that communications with stakeholder groups focused on one threat 359 do not undermine or detract from what is being communicated about the others. Two 360 approaches for overcoming this challenge warrant examination. First, separate the 361 communication of policies to diminish the tension. For example, policies to address water 362 quality (e.g. grants to farmers to implement best water management practice) and COTS 363 (e.g. COTS control) could be communicated as separate programs, even if they are linked in 364 the management strategy. A second approach is to ensure communication, and policies 365 themselves, explicitly address these tensions; for example, explaining how culling COTS will 366 have positive impacts on the Reef's resilience to climate change (Anthony et al. 2015) or 367 how addressing water quality will reduce COTS outbreaks (Wooldridge \& Brodie 2015).

368 Given the 2017 landscape of threat perceptions, a focus on the most widely recognized 369 threats that has positive associations across stakeholders could inform communication of 370 the integrated management strategies to the community, and could have additive effects 371 through providing extra justifications. This means placing most emphasis on the risk posed 372 by climate change, poor water quality, and certain aspects of fishing, and the need for a 373 management approach that articulates multiple threat-mitigating strategies. For example 
using land-based management in combination with marine protected area networks

375 (McCook et al. 2010; MacNeil et al. 2019). For engagement with particular stakeholders,

376 however, we recommend close consideration of the dominant priorities within each group.

377 Consistent and balanced messaging in response to an environmental crisis can help to

378 achieve attitudinal and behavioral change when framed in accordance to people's values

379 (Kochalski et al. 2019; van der Linden et al. 2019). Indeed, in the case of the GBR, this has

380 been suggested in relation to different forms of place attachment (Gurney et al. 2017). Given

381 the strong attachments that people hold for the GBR and the negative emotions or grief they

382 are exhibiting in response to its degradation (Marshall et al. 2019c, 2019a), engagement

383 relating to threats that leverages different forms of attachment to the GBR may hold

384 promise (Smith \& Leiserowitz 2014). Further, targeting messages about the impact of threats

385 on particular habitats (e.g. beaches, estuaries, and iconic reef sites) and species (e.g. whales,

386 turtles, and corals) that stakeholders value (Marshall et al. 2019b) holds additional potential.

387 Finally, leveraging other information channels (e.g. opinion leaders and change agents) and

388 highlighting evidence of effectiveness may have the potential to facilitate impactful

389 messaging that fosters greater stakeholder support for conservation initiatives (Reynolds et

390 al. 2020).

\section{Conclusion}

392 Understanding stakeholders' perceptions of key threats to the natural environment provides 393 critical insights into what kind of management and communication strategies are most likely 394 to resonate with the relevant community. High-profile environmental crises appear to have 395 an important influence on shaping perceptions and may create new opportunities to engage 396 people with mitigation and adaptation. Our approach provides an empirical account of the 397 plasticity of perceptions and shows how stakeholders associate different environmental 398 threats in relation to an iconic natural asset. These findings highlight the importance of 399 further research on this topic and of social monitoring for natural resource management, to 400 understand evolving threat perceptions (and drivers) among different stakeholder groups 401 and communities, providing insights for improved community engagement in threat 402 mitigation policies and actions. Our study further provides guidance for social scientists on 
403 conceptual and empirical approaches and analytical tools to elucidate environmental threat 404 perceptions.

\section{Supporting Information}

406 Community information and survey sample (Appendix S1), the proportion of threat sub-

407 categories across stakeholder groups (Appendix S2), within- and among-stakeholder group

408 variation in threat perception between 2013 and 2017 (Appendix S3), and extend methods

409 for data analysis (Appendix 4) are available online. The authors are solely responsible for the

410 content and functionality of these materials. Queries (other than absence of the material)

411 should be directed to the corresponding author. 


\section{Literature Cited}

Alexander KA, Freeman S, Angel DL. 2018. Public attitudes and decision making in environmental resource planning - a perception gap. Environmental Science \& Policy 80:38-43

Anthony KRN et al. 2015. Operationalizing resilience for adaptive coral reef management under global environmental change. Global Change Biology 21:48-61.

Bacon W. 2013. Sceptical climate part 2: Climate Science in Australian Newspapers. Page Sceptical Climate Part 2:

Bennett NJ, Dearden P. 2014. Why local people do not support conservation: Community perceptions of marine protected area livelihood impacts, governance and management in Thailand. Marine Policy 44:107-116

Boudet H, Giordono L, Zanocco C, Satein H, Whitley H. 2020. Event attribution and partisanship shape local discussion of climate change after extreme weather. Nature Climate Change 10:69-76

Boykoff MT, Boykoff JM. 2007. Climate change and journalistic norms: A case-study of US mass-media coverage. Geoforum 38:1190-1204.

Carmichael JT, Brulle RJ. 2017. Elite cues, media coverage, and public concern: an integrated path analysis of public opinion on climate change, 2001-2013. Environmental Politics 26:232-252

CSIRO. 2019. Social and Economic Long-Term Monitoring Program (SELTMP).

Curnock M et al. 2014. The Social and Economic Long Term Monitoring Program (SELTMP) 2014 Tourism in the Great Barrier Reef. Cairns.

Curnock MI, Marshall NA. 2019. Changes in the state of Great Barrier Reef tourism from 2013 to 2017: a report from the Social and Economic Long-Term Monitoring Program (SELTMP). Townsville.

Curnock MI, Marshall NA, Thiault L, Heron SF, Hoey J, Williams G, Taylor B, Pert PL, Goldberg J. 2019. Shifts in tourists' sentiments and climate risk perceptions following mass coral bleaching of the Great Barrier Reef. Nature Climate Change 9:535-541

D'Anna LM. 2016. Concern is in the eye of the stakeholder: heterogeneous assessments of the threats to oyster survival and restoration in North Carolina. Society \& Natural Resources 29:131-147

de Nooy W. 2013. Communication in Natural Resource Management: Agreement between and Disagreement within Stakeholder Groups. Ecology and Society 18:art44

Eagle L, Hay R, Low DR. 2018. Competing and conflicting messages via online news media: 

Potential impacts of claims that the Great Barrier Reef is dying. Ocean and Coastal Management 158:154-163

Elliott M. 2003. Risk perception frames in environmental decision making. Environmental Practice 5:214-222.

Foxwell-Norton K, Lester L. 2017. Saving the Great Barrier Reef from disaster, media then and now. Media, Culture and Society 39:568-581.

Gattig A, Hendrickx L. 2007. Judgmental discounting and environmental risk perception: dimensional similarities, domain differences, and implications for sustainability. Journal ofSocial Issues 63:21-39.

GBRMPA. 2009. Great Barrier Reef Outlook Report. Townsville.

GBRMPA. 2014. Great Barrier Reef Outlook Report 2014. Great Barrier Reef Marine Park Authority, Townsville.

GBRMPA. 2019a. Great Barrier Reef Outlook Report 2019. Page Great Barrier Reef Marine Park Authority. Townsville.

GBRMPA. 2019b. Position statement: Climate change. Townsville.

Great Barrier Reef blueprint for resilience. 2017. GBRMPA. Townsville.

Gurney GG, Blythe J, Adams H, Adger WN, Curnock M, Faulkner L, James T, Marshall NA. 2017. Redefining community based on place attachment in a connected world. Proceedings of the National Academy of Sciences 114:10077-10082

Gurney GG, Cinner JE, Ban NC, Pressey RL, Pollnac R, Campbell SJ, Tasidjawa S, Setiawan F. 2014. Poverty and protected areas: An evaluation of a marine integrated conservation and development project in Indonesia. Global Environmental Change 26:98-107

Hicks CC, Graham N a J, Cinner JE. 2013. Synergies and tradeoffs in how managers, scientists, and fishers value coral reef ecosystem services. Global Environmental Change 23:14441453

Holmes D, Star C. 2018. Climate change communication in Australia: the politics, mainstream media and fossil fuel industry nexus. Pages 151-170 in W. Leal Filho, E. Manolas, A. M. Azul, U. M. Azeiteiro, and H. McGhie, editors. Handbook of Climate Change Communication: Vol. 1: Theory of Climate Change Communication. Springer International Publishing, Cham.

Horowitz J, Pressey R, Gurney G, Wenger A, Pahang K. 2018. Investigating stakeholder perceptions of fish decline: making sense of multiple mental models. Sustainability 10:1222 
481

Hughes TP et al. 2018. Global warming transforms coral reef assemblages. Nature 556:492496.

Jefferson RL, Bailey I, Laffoley DA, Richards JP, Attrill MJ. 2014. Public perceptions of the UK marine environment. Marine Policy 43:327-337

Kahan DM, Braman D. 2006. Cultural cognition and public policy. ale Law \& Policy Review 24:149-172.

Kasperson RE, Kasperson JX. 1996. The Social Amplification and Attenuation of Risk. The ANNALS of the American Academy of Political and Social Science 545:95-105

Kochalski S, Riepe C, Fujitani M, Aas $\varnothing$, Arlinghaus R. 2019. Public perception of river fish biodiversity in four European countries. Conservation Biology 33:164-175

Lankester AJ, Bohensky E, Newlands M. 2015. Media representations of risk: the reporting of dredge spoil disposal in the Great Barrier Reef Marine Park at Abbot Point. Marine Policy 60:149-161

Lee TM, Markowitz EM, Howe PD, Ko CY, Leiserowitz AA. 2015. Predictors of public climate change awareness and risk perception around the world. Nature Climate Change 5:10141020.

Mackeracher T, Diedrich A, Gurney GG, Marshall N. 2018. Who trusts whom in the Great Barrier Reef? Exploring trust and communication in natural resource management. Environmental Science \& Policy 88:24-31

MacNeil MA, Mellin C, Matthews S, Wolff NH, McClanahan TR, Devlin M, Drovandi C, Mengersen K, Graham NAJ. 2019. Water quality mediates resilience on the Great Barrier Reef. Nature Ecology \& Evolution 3:620-627

Marshall N, Adger WN, Benham C, Brown K, I Curnock M, Gurney GG, Marshall P, L Pert P, Thiault L. 2019a. Reef Grief: investigating the relationship between place meanings and place change on the Great Barrier Reef, Australia. Sustainability Science 14:579-587

Marshall N, Curnock M. 2019a. Changes among Great Barrier Reef commercial fishers from 2013 to 2017: a report from the Social and Economic Long-Term Monitoring Program (SELTMP). Page (GBRMPA, editor). Townsville.

Marshall NA, Bohensky E, Curnock M, Goldberg J, Gooch M, Nicotra B, Pert P, Scherl LM, Stone-Jovicich S, Tobin RC. 2016. Advances in monitoring the human dimension of natural resource systems: An example from the Great Barrier Reef. Environmental Research Letters 11:1-17

Marshall NA, Curnock MI. 2019b. Changes among coastal residents of the Great Barrier Reef region from 2013 to 2017. Report from the Social and Economic Long-Term Monitoring 
Marshall NA, Dunstan P, Pert P, Thiault L. 2019b. How people value different ecosystems within the Great Barrier Reef. Journal of Environmental Management 243:39-44

Marshall NA, Thiault L, Beeden A, Beeden R, Benham C, Curnock M, Diedrich A, Gurney G, Jones L, Marshall PA. 2019c. Our environmental value orientations influence how we respond to climate change. Frontiers in Psychology 10:938

McCook LJ et al. 2010. Adaptive management of the Great Barrier Reef: a globally significant demonstration of the benefits of networks of marine reserves. Proceedings of the National Academy of Sciences of the United States of America 107:18278-85

Mellin C et al. 2019. Spatial resilience of the Great Barrier Reef under cumulative disturbance impacts. Global Change Biology:1-15 gcb.14625.

Morrison TH, Hughes TP, Adger WN, Brown K, Barnett J, Lemos MC. 2019. Save reefs to rescue all ecosystems. Nature 573:333-336

Moscardo G. 2008. Exploring public awareness of threats to the Great Barrier Reef environment. Interdisciplinary Environmental Review 10:45-64.

Opray M. 2019, November. Peter Ridd and the climate sceptics. The Saturday Paper.

Pollnac R, Christie P, Cinner JE, Dalton T, Daw TM, Forrester GE, Graham N a J, McClanahan TR. 2010. Marine reserves as linked social-ecological systems. Proceedings of the National Academy of Sciences of the United States of America 107:18262-5

R Core Team. 2017. R: A language and environment for statistical computing. R Foundation for Statistical Computing, Vienna, Austria. Available from http://www.r-project.org/.

Reynolds JP, Stautz K, Pilling M, van der Linden S, Marteau TM. 2020. Communicating the effectiveness and ineffectiveness of government policies and their impact on public support: a systematic review with meta-analysis. Royal Society Open Science 7:190522

Richardson LE, Graham NAJ, Pratchett MS, Eurich JG, Hoey AS. 2018. Mass coral bleaching causes biotic homogenization of reef fish assemblages. Global Change Biology 24:31173129

Siegrist M. 2013. The necessity for longitudinal studies in risk perception research. Risk Analysis 33:50-51

Slovic P. 1999. Trust, emotion, sex, politics, and science: Surveying the risk-assessment battlefield (Reprinted from Environment, ethics, and behavior, pg 277-313, 1997). Risk Analysis 19:689-701.

Smith N, Leiserowitz A. 2014. The role of emotion in global warming policy support and opposition. Risk Analysis 34:937-948. 
Stafford R, Jones PJS. 2019. Viewpoint - Ocean plastic pollution: A convenient but distracting truth? Marine Policy 103:187-191.

Sutton SG, Tobin RC. 2009. Recreational fishers' attitudes towards the 2004 rezoning of the Great Barrier Reef Marine Park. Environmental Conservation 36:245-252.

Tobin R, Bohensky E, Curnock M, Goldberg J, Gooch M, Marshall N, Nicotra B, Pert P, Scherl L, Stone-Jovicich S. 2014. The Social and Economic Long Term Monitoring Program (SELTMP) 2014 - Commercial Fishing in the Great Barrier Reef. Cairns.

Ungar S. 2014. Media context and reporting opportunities on climate change: 2012 versus 1988. Environmental Communication 8:233-248

van der Linden S. 2019. Countering science denial. Nature Human Behaviour 3:889-890

van der Linden S, Maibach E, Leiserowitz A. 2019. Exposure to scientific consensus does not cause psychological reactance. Environmental Communication 0:1-8

Voyer M, Dreher T, Gladstone W, Goodall H. 2013. Who cares wins: The role of local news and news sources in influencing community responses to marine protected areas. Ocean \& Coastal Management 85:29-38

Wolf J, Moser SC. 2011. Individual understandings, perceptions, and engagement with climate change: insights from in-depth studies across the world. Wiley Interdisciplinary Reviews: Climate Change 2:547-569

Wooldridge SA, Brodie JE. 2015. Environmental triggers for primary outbreaks of crown-ofthorns starfish on the Great Barrier Reef, Australia. Marine Pollution Bulletin 101:805- 


\section{Table}

572 Table 1: Threat categories used to categorize survey participants responses to the open-ended

573 question "what are the three most serious threats to the Great Barrier Reef?". See Supporting 574 Information for distribution of sub-categories and Curnock et al. (2019) for the process for 575 identifying the categories.

\begin{tabular}{ll}
\hline Threat categories & Example responses \\
\hline Climate change & $\begin{array}{l}\text { Climate change; global or ocean warming; rising temperatures; sea } \\
\text { level rise; ocean acidification; coral bleaching }\end{array}$ \\
\hline Pollution & Pollution; marine debris; litter; plastic; rubbish \\
\hline Poor water quality & $\begin{array}{l}\text { Agricultural, urban and industrial runoffs; sediments; pesticides; } \\
\text { sewage; fertilizers }\end{array}$ \\
\hline Coastal development & $\begin{array}{l}\text { Port expansions; dredging; infrastructures; harbors; coastal } \\
\text { development }\end{array}$ \\
\hline $\begin{array}{l}\text { Crown-of-thorns starfish } \\
\text { (COTS) }\end{array}$ & COTS; the starfish \\
\hline Fishing & Commercial and recreational fishing and collecting; illegal foreign \\
& and domestic fishing; overfishing; poaching \\
\hline Shipping & Shipping traffic; collisions; oil spills; big tanker ships; ballast waters \\
\hline Natural disaster & Natural disasters; storms; cyclones; floods; tsunamis; earthquakes \\
\hline Governance & $\begin{array}{l}\text { Mismanagement; bureaucracy; politics; lack of enforcement; } \\
\text { corruption; lack of government support or involvement }\end{array}$ \\
\hline Tourism & Tourism; trampling; diver impacts; unsustainable tourism \\
\hline Mining & Mining industry; Adani; coal \\
\hline Humanity & $\begin{array}{l}\text { Overpopulation; damage from humans; human activities; bad } \\
\text { human behavior; people; societal attitudes }\end{array}$ \\
\hline Other & Habitat loss; invasive species; other \\
\hline
\end{tabular}




\section{Figure legends}

578 Figure 1: Changes in the environmental threat perceptions of stakeholder groups between

5792013 and 2017. Solid points represent occurrence probability estimates and error bars the

580 bootstrapped $95 \%$ confidence intervals. Red and blue colors respectively indicate significant

581 increases and decreases in threat occurrence probability within the stakeholder groups over

582 time. OR: odds ratio. OR $>1$ indicates increased odds of identifying a given threat among the

583 three most serious threats to the GBR. Only the eight most frequently reported threats are

584 displayed. See Supporting Information for results for all threat categories $(n=12)$ except

585 'other'.

586 Figure 2: Changes in the rankings of perceived threats to the GBR between 2013 and 2017 587 across stakeholder groups. The thickness of a band indicates the probability of a particular 588 threat being identified as one of the three most serious threats to the GBR (thicker band 589 means higher probability).

590 Figure 3: Variation in threat perceptions among stakeholder groups in 2013 (yellow) and 2017 591 (green). Different letters at the top of bars indicate significant differences among stakeholder 592 groups within each year, as revealed by generalized linear models. N.S.: not significant; F: 593 commercial fishers; O: tourism operators; R: coastal residents. The eight most frequently 594 identified threats are displayed. See Supporting Information for results for all 12 threat 595 categories except 'other'.

$596 \quad$ Figure 4: Network diagrams showing interactions among threats prioritized as most serious to 597 the Great Barrier Reef by commercial fishers, tourism operators, and residents in 2013 and 598 2017, based on co-occurrence analysis. The size of the node reflects the threat's occurrence 599 probability (larger node means higher probability). Green ties (interactions) indicate non600 random tendencies to co-occur and orange ties indicate non-random tendencies to be 601 associated negatively between pairs of threats (nodes). Ties are only highlighted where the 602 observed frequency of interaction differs from expected random frequency. 


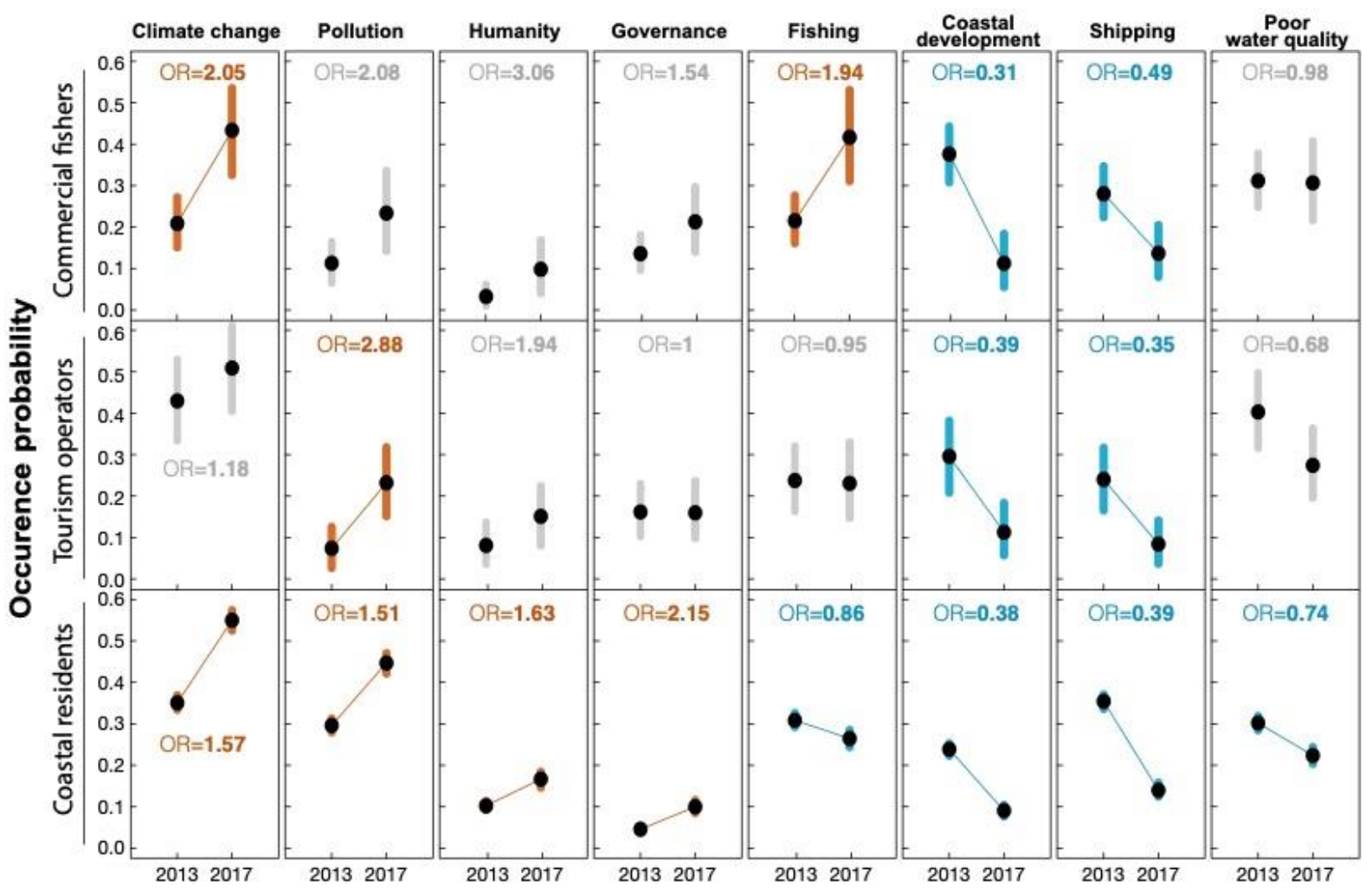

606 Figure 1: Changes in the environmental threat perceptions of stakeholder groups between 6072013 and 2017. Solid points represent occurrence probability estimates and error bars the 608 bootstrapped 95\% confidence intervals. Red and blue colors respectively indicate significant 609 increases and decreases in threat occurrence probability within the stakeholder groups over 610 time. OR: odds ratio. $O R>1$ indicates increased odds of identifying a given threat among the 611 three most serious threats to the GBR. Only the eight most frequently reported threats are 612 displayed. See Supporting Information for results for all threat categories $(n=12)$ except 613 'other'. 

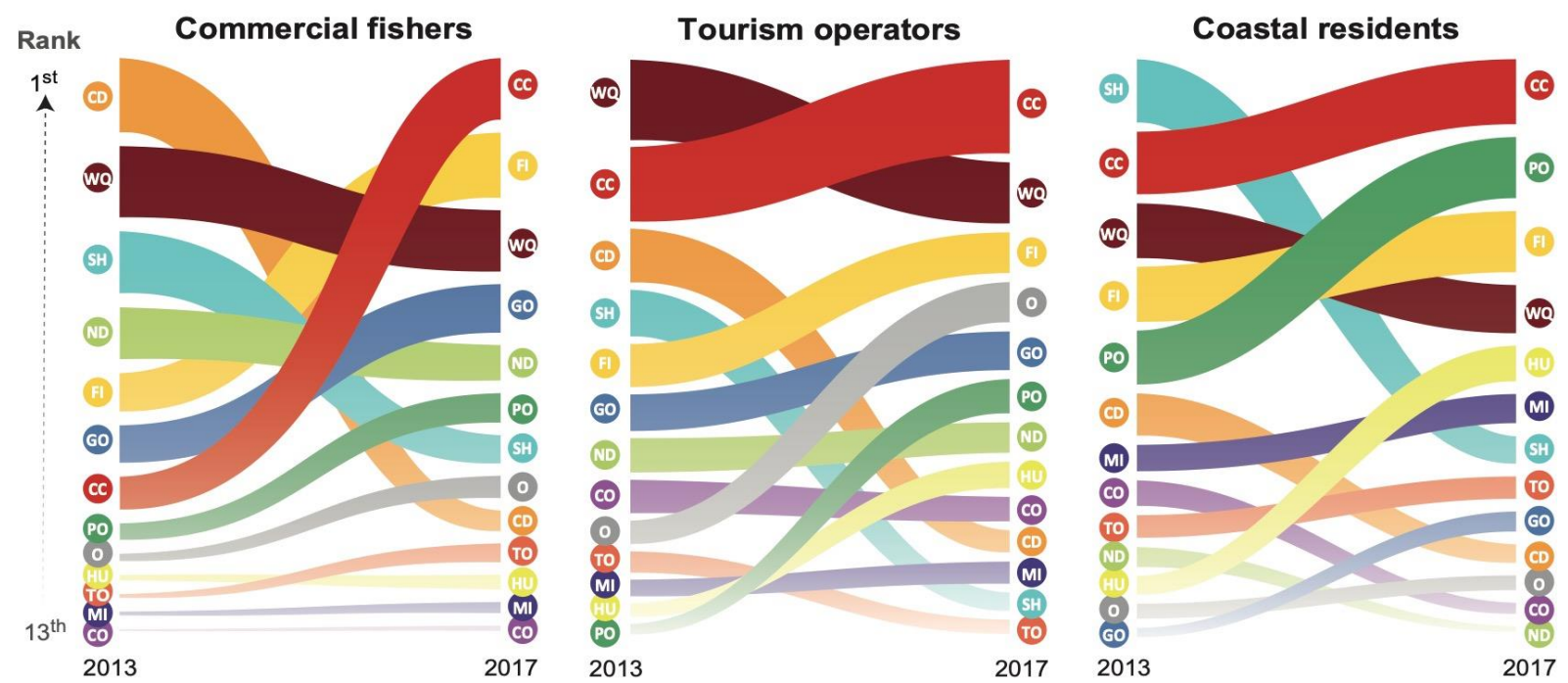

(v) Poorwater quality

(CD) Coastal development

(NiD) Natural disasters

() Governance

(c) Other

cc Climate change

(1) Pollution

(Mi) Mining

(10) Tourism

(i) Fishing

(파) Shipping

(๖) COTS

615 Figure 2: Changes in the rankings of perceived threats to the GBR between 2013 and 2017 across stakeholder groups. The thickness of a band indicates the probability of a particular threat being identified as one of the three most serious threats to the GBR (thicker band means higher probability). 

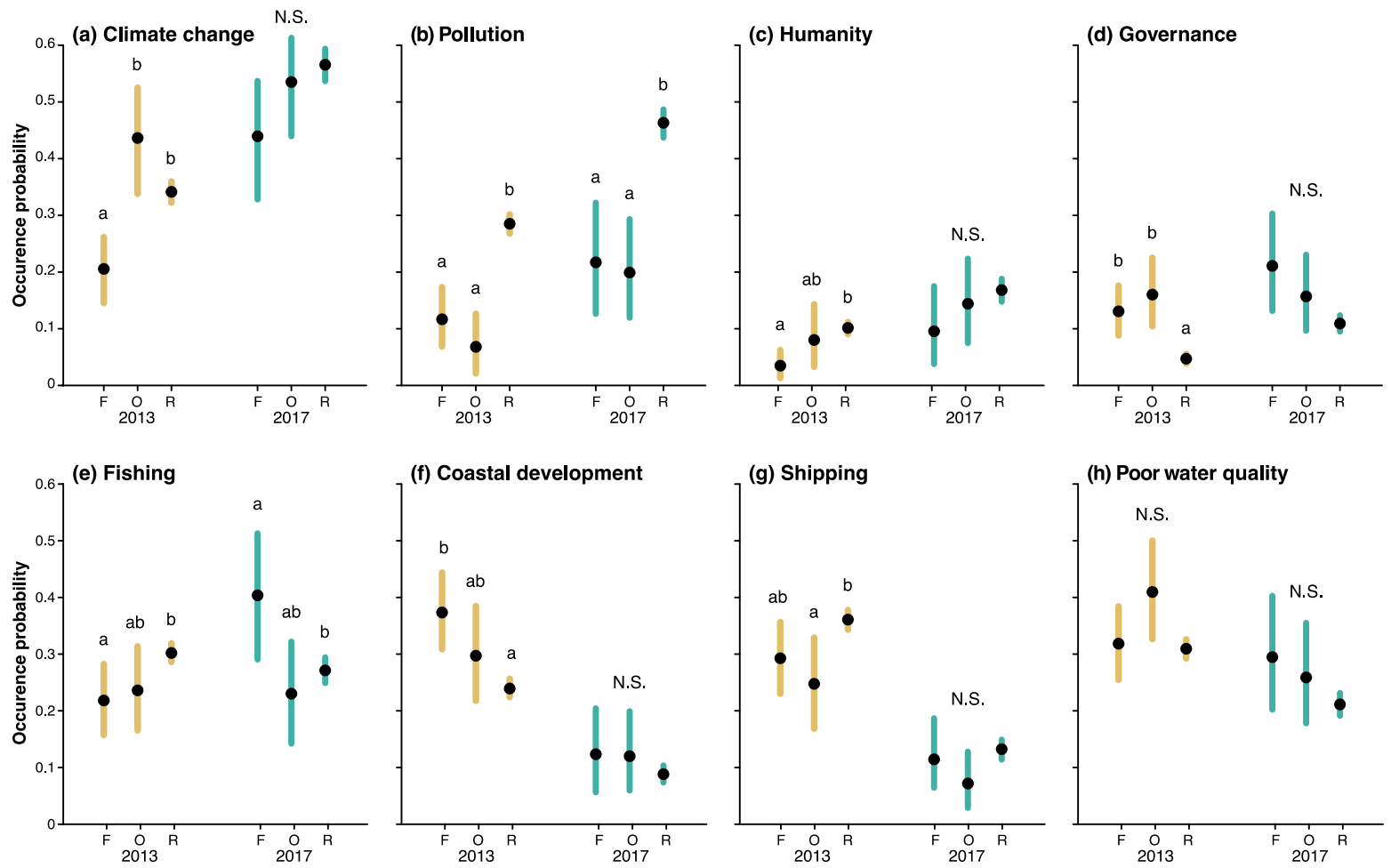

620 Figure 3: Variation in threat perceptions among stakeholder groups in 2013 (yellow) and 2017

621 (green). Different letters at the top of bars indicate significant differences among stakeholder groups within each year, as revealed by generalized linear models. N.S.: not significant; F: commercial fishers; O: tourism operators; R: coastal residents. The eight most frequently identified threats are displayed. See Supporting Information for results for all 12 threat 625 categories. except 'other'. 

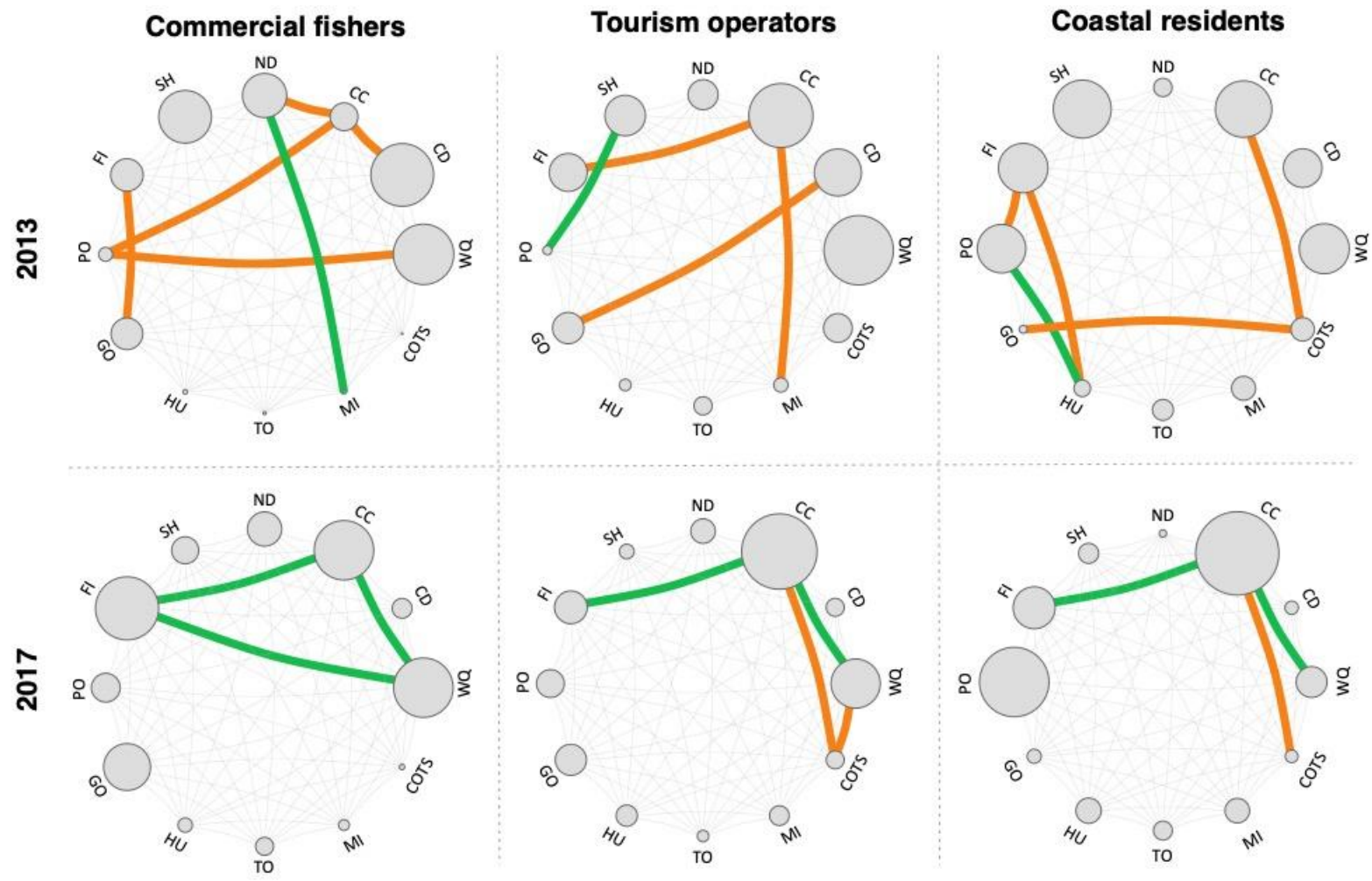

cC Climate change

CD Coastal development

ND Natural disasters WQ Water quality

TO Tourism

HU Humanity

PO Pollution

CT COTS

MI Mining

GO Governance

Positively associated

627 Figure 4: Network diagrams showing interactions among threats prioritized as most serious to 628 the Great Barrier Reef by commercial fishers, tourism operators, and residents in 2013 and 629 2017, based on co-occurrence analysis. The size of the node reflects the threat's occurrence 630 probability (larger node means higher probability). Green ties (interactions) indicate non631 random tendencies to co-occur and orange ties indicate non-random tendencies to be associated negatively between pairs of threats (nodes). Ties are only highlighted where the observed frequency of interaction differs from expected random frequency. 